\title{
Prevalence of hyperthyroidism, hypothyroidism, and euthyroidism in thyroid eye disease: a systematic review of the literature
}

Juliana Muñoz-Ortiz ${ }^{1,2}$, Maria Camila Sierra-Cote², Estefanía Zapata-Bravo², Laura Valenzuela-Vallejo², Maria Alejandra Marin-Noriega², Pilar Uribe-Reina 1,2, Juan Pablo Terreros-Dorado², Marcela Gómez-Suarez Karla Arteaga-Rivera ${ }^{1}$ and Alejandra de-la-Torre ${ }^{2^{*}}$ (D)

\begin{abstract}
Background: Thyroid eye disease is an autoimmune disorder of the orbital retrobulbar tissue commonly associated with dysthyroid status. The most frequent condition is hyperthyroidism, although it is also present in hypothyroid and euthyroid patients. The prevalence of thyroid conditions in patients with thyroid eye disease had been previously evaluated; however, there is no consensus on a global prevalence. The study aims to estimate the prevalence of hyperthyroidism, hypothyroidism, and euthyroidism in patients with TED, through a systematic review of literature.

Methods: We conducted a systematic review of the literature following the PRISMA guidelines, in MEDLINE, COCHRANE, EMBASE, Science Direct, and LILACS databases. Inclusion criteria were primary studies of patients with a diagnosis of thyroid eye disease made by an ophthalmologist or with diagnosis criteria, with measurement of thyroid function (TSH, T3, and free T4), and diagnosis of the primary thyroid condition. A quality assessment was made through the Joanna Briggs Institute Quality tools. Finally, we extracted relevant details about the design, the results, and the prevalence of thyroid disorders in thyroid eye disease.
\end{abstract}

Results: The initial search revealed 916 studies, of which finally thirteen met inclusion criteria. Six studies were performed in Europe (Germany, Wales, and Spain), five in Asia (Iran, South Korea, Japan, and Singapore), one in North America (USA), and one in Africa (Ghana). The global prevalence, in patients of thyroid eye disease, was 10.36\% for hypothyroidism, 7.9\% for euthyroidism, and $86.2 \%$ for hyperthyroidism.

Conclusions: Professionals should be aware that thyroid eye disease can be present in patients with a normal thyroid function. The assessment for these patients is based on orbital images; serum TSH, T3, and free T4; antibody levels as thyrotropin receptor antibodies; and thyroperoxidase levels. Additionally, we want to encourage research in this field in other regions of the world such as Latin America.

Systematic review registration: PROSPERO ID CRD42020107167

Keywords: Dysthyroid ophthalmopathy, Hypothyroidism, Hyperthyroidism, Euthyroid, Prevalence

\footnotetext{
* Correspondence: alejadelatorre@yahoo.com

${ }^{2}$ Research Group in Neurosciences NeURos, Escuela de Medicina y Ciencias de la Salud, Universidad del Rosario, Carrera 24 \# 63C 69, Bogotá, Colombia Full list of author information is available at the end of the article
}

(c) The Author(s). 2020 Open Access This article is licensed under a Creative Commons Attribution 4.0 International License, which permits use, sharing, adaptation, distribution and reproduction in any medium or format, as long as you give appropriate credit to the original author(s) and the source, provide a link to the Creative Commons licence, and indicate if changes were made. The images or other third party material in this article are included in the article's Creative Commons licence, unless indicated otherwise in a credit line to the material. If material is not included in the article's Creative Commons licence and your intended use is not permitted by statutory regulation or exceeds the permitted use, you will need to obtain permission directly from the copyright holder. To view a copy of this licence, visit http://creativecommons.org/licenses/by/4.0/. The Creative Commons Public Domain Dedication waiver (http://creativecommons.org/publicdomain/zero/1.0/) applies to the data made available in this article, unless otherwise stated in a credit line to the data. 


\section{Background Rationale}

Thyroid disease (TD) is a quite common condition worldwide. According to the American Thyroid Association, only in the United States of America (USA) reported 20 million Americans with some form of TD, and at least $12 \%$ will develop a thyroid condition during their lifetime. According to hormonal levels, the patients with TD can be classified into three different groups: hypothyroidism, euthyroidism, and hyperthyroidism [1].

Euthyroidism is defined as normal thyroid hormone production and serum levels [2]. Hyperthyroidism is a clinical condition in which thyroid hormones are synthesized excessively. The reported prevalence is $0.8 \%$ in the USA and $1.3 \%$ in Europe. It is seen more frequently in women and adulthood. The clinical manifestations usually involve several systems, for example, weight loss can be evidenced despite no appetite disturbance, limb tremor, tachycardia, and tachypnea [3]. On the contrary, hypothyroidism is the condition in which thyroid hormones are deficient. It has a higher prevalence that varies between 0.3 and $3.7 \%$ in the USA and 0.2 and $5.3 \%$ in Europe. It occurs more frequently in women over 65 years of age and it is commonly seen in patients with autoimmune diseases, such as type 1 diabetes mellitus and celiac disease, among others. The clinical manifestations are usually weight gain, fatigue, and cold intolerance [4].

Thyroid eye disease (TED) is an autoimmune disorder of the orbital retrobulbar tissue associated with dysthyroidism, mainly hyperthyroidism in Graves' disease (GD), even though it is present in hypothyroid and euthyroid patients [5].

The prevalence of dysthyroidism in patients with TED has been previously evaluated; however, there is no consensus on a global prevalence, and the physiopathological effect of thyroid hormones on the onset and progression of TED has not been fully understood.

The thyroid-stimulating hormone receptor (TSHr) and insulin-like growth factor 1 (IGF-1) receptor on orbital fibroblasts are likely to be the most important autoimmune targets in the disease. It has been hypothesized that clinical phenotypes such as euthyroid or hypothyroid TED, or the predominance of muscle or fat enlargement, may be caused by the molecular signature of different anti-thyrotropin-receptor antibodies [6]. Also, previous studies had concluded that dysthyroidism (hyperthyroidism or hypothyroidism) is associated with more severe presentations of TED, recommending the assessment of thyroid function during antithyroid treatment and the management of TED [7].

The study aims to estimate the prevalence of hyperthyroidism, hypothyroidism, and euthyroidism in patients with TED, through a systematic review of literature.

\section{Description of the condition}

TED is the most common autoimmune disease of the orbit [8]. The disease appears two to six times more frequent in young women, but severe cases occur more frequently in men older than 50 years [8].

In TED's physiopathology, the orbit becomes infiltrated by $\mathrm{B}$ and $\mathrm{T}$ cells, activating genes involved in inflammation and tissue remodeling [9]. Orbital fat and extraocular muscles expand from accumulating hyaluronidase-digestible material and adipogenesis [6]. These events are mediated by interleukins $1 \beta, 6,8$, and 16; tumor necrosis factor $\alpha$ (TNF- $\alpha$ ); RANTES (regulated on activation, normal $\mathrm{T}$ cell expressed and secreted); and CD40 ligand. The action of these cytokines turns bone marrow-derived fibrocytes into CD34+ fibroblasts that further differentiate into myofibroblasts or adipocytes [10].

The CD34+ fibroblasts express low levels of TSHr and other thyroid antigen receptors and overexpress IGF-1 receptors [11-13]. Thyroid-stimulating immunoglobulins activate the IGF-1 receptor complex, leading to the expression of inflammatory molecules and glycosaminoglycan synthesis; this signaling can also be activated in adipocytes [10].

Clinical manifestations of TED mainly include eyelid retraction (90\%), exophthalmos (62\%), restricted extraocular motility (43\%), eye pain (30\%), tearing (21\%), diplopia (17\%), photophobia (16\%), blurred vision (8\%), and optic nerve dysfunction (6\%) [14]. Patients with euthyroid/hypothyroid TED developed significantly less severe ocular symptoms, less active, and more asymmetrical disease than hyperthyroid patients [15].

TED management starts with the control of environmental factors to decrease the risk of disease progression, such as smoking cessation. Local management of TED includes ocular lubrication, conjunctival autograft, or even orbital decompression in severe cases. The oral glucocorticoids are recommended to be administered as prophylaxis for mild active TED when treated with radioactive iodine in patients with GD. Intravenous glucocorticoids are the first line of treatment for moderateto-severe and active TED. Options for disease maintenance are many and include orbital radiotherapy, selenium, cyclosporine, azathioprine, mycophenolate mofetil, tocilizumab, or rituximab [16]. Recently, a new pharmaceutic molecule was approved for TED, teprotumumab. This is a fully human monoclonal antibody that attenuates signaling initiated at the IGF-1 receptor complex blocking pathologic immune responses [17].

\section{Description of the thyroid function measurement and the diagnosis of the primary thyroid condition}

Thyroid function measurement is made from the level of hormones produced by the thyroid gland and the hormone that stimulates its production. The normal thyroid 
function is called euthyroidism, described by the American Thyroid Association as a normal range between 0.4 and $4.0 \mathrm{mU} / \mathrm{L}$ for thyroid-stimulating hormone (TSH) [18]. On the other hand, hyperthyroidism presents elevated free thyroxine (T4) and triiodothyronine (T3) and decreased TSH serum levels (0.0-0.4 mU/L) [3]. Besides, hypothyroidism is diagnosed with elevated serum concentration of TSH (above $4.0 \mathrm{mU} / \mathrm{L}$ ) and decreased free T4 levels [18].

How the thyroid function measurement and the diagnosis of the primary thyroid condition might work

By measuring the TSH, T3, and free T4 levels in TED patients, the thyroid function can be objectively evaluated and classified. The prevalence report of these conditions will allow the calculation of weighted prevalence.

\section{Why it is important to do this review}

The prevalence of TED in hyperthyroidism is very well described because of its high prevalence. However, the low prevalence calculation in hypothyroid and euthyroid patients with the ophthalmological condition means that in clinical practice, these patients are initially ruled out for the TED study. Diagnosis could be in a late stage with a delay in treatment initiation and complications development.

\section{Objective}

The study aims to estimate the prevalence of hyperthyroidism, hypothyroidism, and euthyroidism in patients with TED, through a systematic review of literature.

\section{Methods}

\section{Protocol and registration}

The present review was performed according to the Preferred Reporting Items for Systematic Reviews and meta-analysis (PRISMA) guidelines [19]. The protocol registration can be found under the PROSPERO ID CRD42020107167.

\section{Study design}

The study design is a systematic review of literature evaluating the prevalence of primary hyperthyroidism, hypothyroidism, and euthyroidism in patients with TED diagnosis.

\section{Eligibility criteria}

We included all published articles if (a) the abstract was available; (b) it contained original data; (c) the TED was diagnosed by an ophthalmologist or diagnosis criteria were settled; (d) the thyroid disorders were measured with blood levels of TSH, free T4, and T3 [3, 18]; and (e) if it reported the prevalence of primary thyroid function variation on TED patients. If the prevalence was not reported but was possible to calculate it, the study was also included. Articles were excluded from the analysis if the diagnosis of the thyroid function status were secondary to thyroid disease treatment or if the study design was a review, letter to the editor, case report, case series, or systematic reviews.

\section{Information sources}

We used a combination of exploded controlled vocabulary (MeSH, Emtree, DeCS) and free-text terms (considering spelling variants, plurals, synonyms, acronyms, and abbreviations) with field labels, truncation, proximity operators, and Boolean operators.

The literature search was conducted in the following electronic databases up to July 29 of 2019: MEDLINE, COCHRANE, EMBASE, ScienceDirect, and LILACS. No limits regarding language and period of publication were used (Additional file 1). The search was updated on April 21 of 2020.

\section{Study selection}

The electronic search was made by two reviewers (JMO and MCSC). Duplicates were eliminated through an Excel function. We performed an independent review of article titles and abstracts extracting data according to the predefined eligibility criteria. In case of disagreement, a third reviewer (ADLT) made the inclusion decision (Fig. 1).

\section{Data collection process}

A data collection form was designed in Excel. Three reviewers (MCSC, EZB, and LVV) independently extracted relevant details about the design and the results of each study which included author, study period, location, study design, number of patients with TED, and the prevalence of primary hyperthyroidism, hypothyroidism, and euthyroidism.

\section{Risk of bias}

We followed the chapter of systematic reviews of prevalence and incidence of the Johanna Briggs Institute (JBI) to conduct this systematic review and classified the articles using the respective tool for each study design [20, 21]. An expert methodologist (MGS) established cutting points for the minimum score acceptable for study inclusion: $72 \%$ for cohort studies, $75 \%$ for cross-sectionals, and $80 \%$ for case-control, or if any of it met all our major inclusion criteria [21] (Additional file 2).

\section{Results}

\section{General description}

Our search strategy extracted 916 published articles (199 from MEDLINE, 570 from Embase, 127 from ScienceDirect, 14 from Cochrane and 6 from LILACS). 

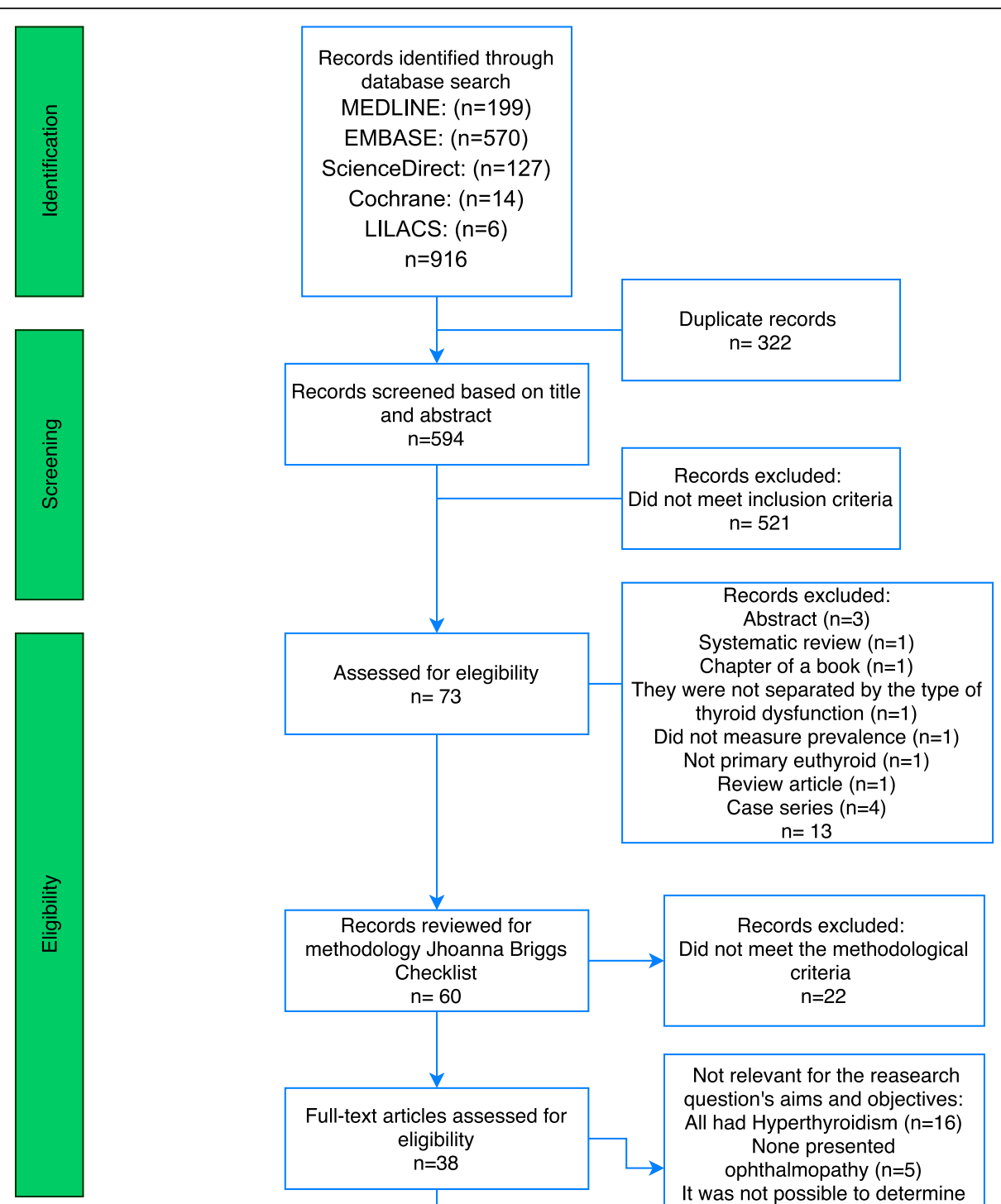

Not relevant for the reasearch question's aims and objectives: All had Hyperthyroidism $(n=16)$ None presented ophthalmopathy $(n=5)$ It was not possible to determine the prevalence $(n=3)$

Duplicate publication $(n=1)$ $n=25$
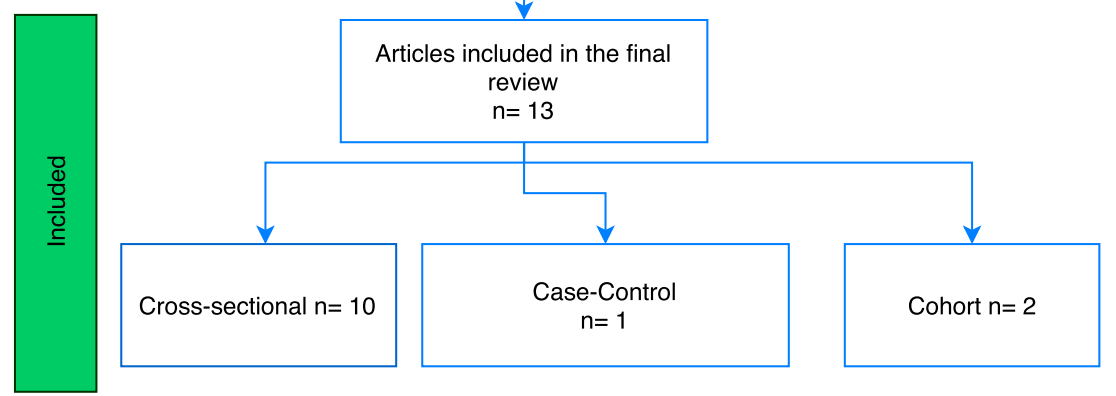

Fig. 1 PRISMA flowchart

After screening, 73 articles were assessed for eligibility and only 60 met the selection criteria and were evaluated through the JBI quality tool; 38 full-text articles were assessed for eligibility. Finally, after discarding 25 articles for different reasons (all the patients had hyperthyroidism, did not present ophthalmopathy, or it was not possible to determine the prevalence) 14 articles met all the inclusion criteria, but two articles had the 
same sample because they were made in the same population. To avoid overrepresentation of this crosssectional study, we included only the data of one of them [22, 23] (Fig. 1) (Additional file 3).

\section{Characteristics}

Our final inclusion strategy yielded 13 published articles, 6 were conducted in Europe (Germany, Wales, and Spain), 5 in Asia (Iran, Korea, Japan, and Singapore), one in North America (USA), and one in Africa (Ghana). All the studies were published between 1996 and 2018. Two of the studies had a small sample size of TED patients (18 and 47) and the rest had a bigger population (between 103 and 1020). All patients had a diagnosis of TED and thyroid function had been measured with TSH, free T4 levels, and T3 (if needed) or had it initially as an inclusion criteria (Tables 1 and 2).

\section{General description of the included studies Cohort studies}

Of the 13 studies, two were cohort studies $[15,27]$. The first one, performed by Eckstein et al., reported on a retrospective study from a TED database 182 consecutive patients treated at the University Hospital of Essen, Germany [15]. The second one was made between 1996 and 1999 in Asia, the sample was of 1020 patients with TED diagnosis, and 1001 were excluded in their analysis study because they had the previous history of thyrotoxicosis or hyperthyroidism (we included these patients into the hyperthyroid group of our study). Ten had subclinical thyrotoxicosis (these patients were added to the hyperthyroid group in our study), and the other nine patients were in hypothyroid or euthyroid status [27].

\section{Cross-sectional studies}

Ten articles were cross-sectional studies and published between 1996 and 2018. One of the studies was conducted in the USA, and the rest in Wales, Germany, Spain, Iran, Japan, and Ghana. The population's range within the studies was between 18 and 610 patients; the ten articles had individuals with TED and primary hyperthyroidism, with a calculated prevalence of $85.7 \%$ in the ranges of $65.7-95.7 \%$. In eight articles, primary hypothyroidism was present in TED individuals, with a calculated prevalence of $12.18 \%$ between 2.6 and $33.3 \%$ and euthyroid patients with TED was present in six articles without a history of dysthyroidism, with a calculated prevalence of $6.7 \%$ with a range between 0.9 and $13.6 \%$. Data from a referral endocrinology clinic (Tehran University Institute of Endocrinology) were overrepresented and two studies pertained to the same population.

\section{Case-control studies}

The case-control study published by Jang et al. determined the clinical and biochemical characteristics of 163 Korean patients with TED between 2008 and 2010 [26].

\section{Thyroid states \\ Hyperthyroidism}

The thirteen studies reported the presence of primary hyperthyroidism in patients with TED. Some of the studies reported GD $[25,28,30,31]$ as the primary cause of hyperthyroidism. The range of prevalence was between (65.7-99.1\%), with a total calculated prevalence of 86.2\%. Countries like Wales (93,6\%), USA (90\%), and Iran $(92,4 \%)$ had a higher prevalence, in contrast to another study in Wales with $65.7 \%$ and Spain that had the lowest prevalence (66.7\%) (Fig. 2).

\section{Hypothyroidism}

Ten studies (eight cross-sectional and two cohorts) reported the presence of primary hypothyroidism patients presenting TED, with a range of prevalence between 0.2 and $33.3 \%$ and a total calculated prevalence of $10.36 \%$, where Spain showed the higher prevalence and Singapore the lowest. Some of them with the diagnosis of Hashimoto hypothyroidism [25]. All patients with secondary hypothyroidism (after treatment for any dysthyroidism with thyroidectomy, ion ablation, or radiation) were excluded (Fig. 3).

\section{Euthyroidism}

Nine of the 13 studies had TED patients with euthyroidism. The prevalence ranges from $0.9 \%$ in Iran and $15.4 \%$ in Germany. With a total calculated prevalence of $7.9 \%$, the studies were located in Ghana, USA, Germany, Korea, Iran, Singapore, Japan, and Wales. The TED sample size ranges from 103 to 1020 patients (Fig. 4).

\section{Discussion}

\section{Context}

TD is a widely common endocrine pathology. According to the American Thyroid Association, nearly $12 \%$ of the USA population develop any thyroid condition during their life, and closely 20 million Americans have some form of TD. Thyroid disbalances can cause certain serious consequences, such as cardiovascular diseases, osteoporosis, complications during pregnancy, and infertility [1]. One important manifestation of TD is TED. This condition can significantly decrease the quality of life of those who suffer it due to its signs and symptoms [34].

The importance of this study lies in providing information about the level of thyroid hormones in patients with TED, to correctly differentiate Graves' ophthalmopathy (GO) and TED. This confusion occurs since most patients with TED have biochemical evidence of hyperthyroidism with the most common cause being GD; however, TED may occur in patients with hypothyroidism (mainly Hashimoto's thyroiditis) or euthyroidism [35]. 


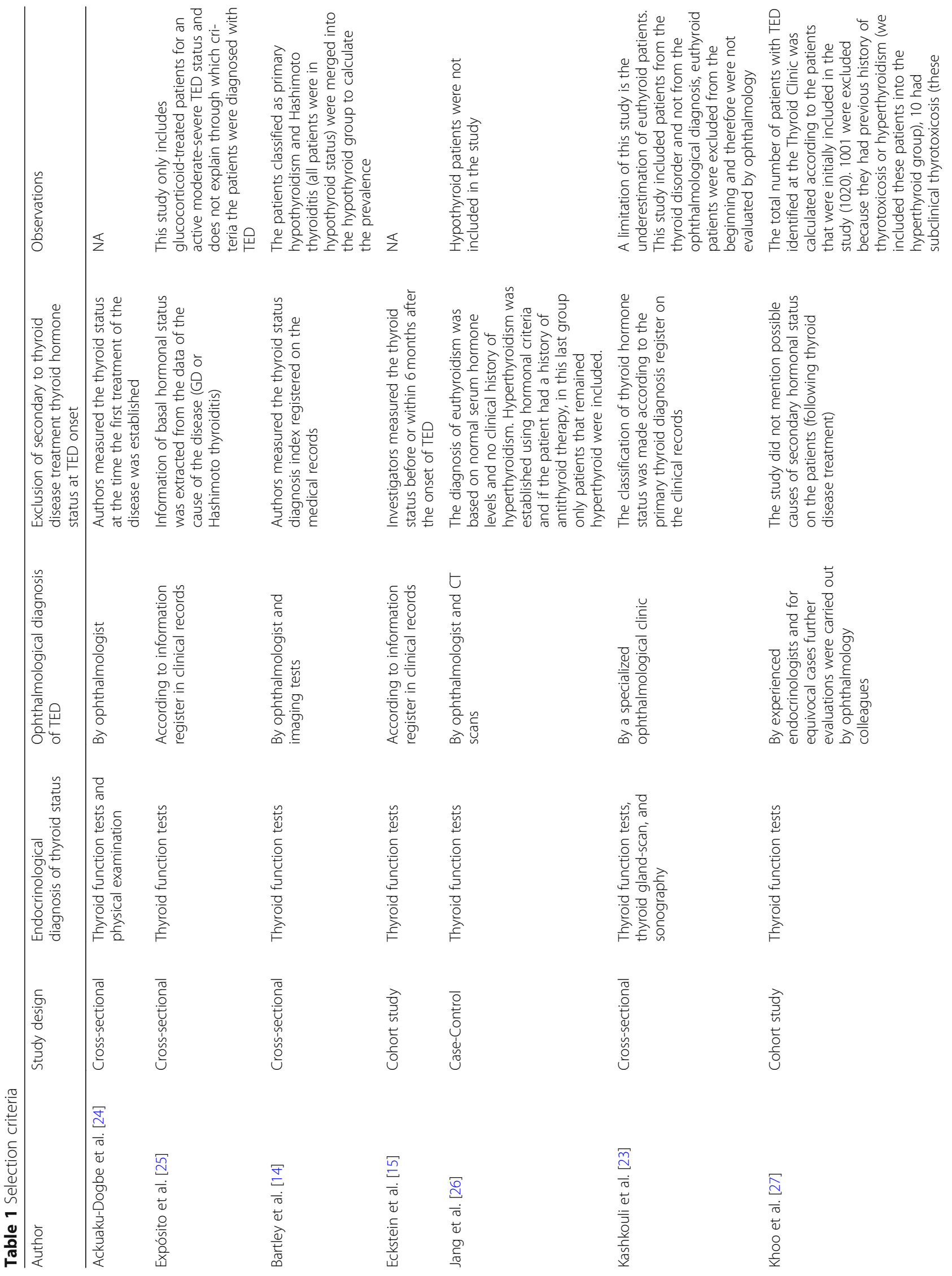




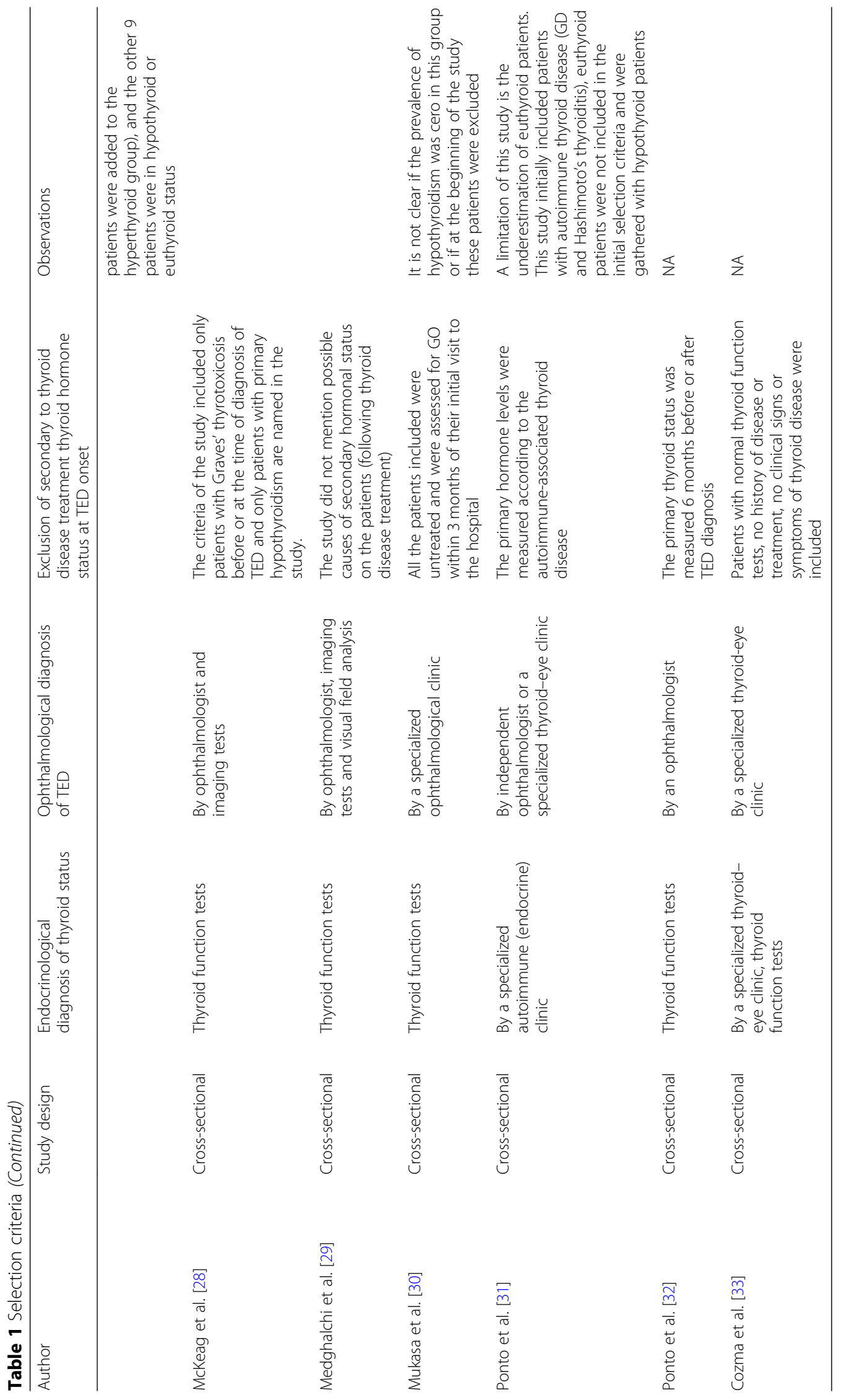


Table 2 Characteristics of included studies

\begin{tabular}{|c|c|c|c|c|c|c|}
\hline Author & Study period & Country & $\begin{array}{l}\text { Number of patients } \\
\text { with TED }\end{array}$ & $\begin{array}{l}\text { Prevalence (\%) } \\
\text { hyperthyroidism in TED }\end{array}$ & $\begin{array}{l}\text { Prevalence (\%) } \\
\text { hypothyroidism in TED }\end{array}$ & $\begin{array}{l}\text { Prevalence (\%) } \\
\text { euthyroidism in TED }\end{array}$ \\
\hline Ackuaku-Dogbe et al. [24] & $2014-2016$ & Ghana & 117 & $104(88.9)$ & $5(4.3)$ & $8(6.8)$ \\
\hline Expósito et al. [25] & $2007-2011$ & Spain & 18 & $12(66.7)$ & $6(33.3)$ & - \\
\hline Bartley et al. [14] & 1976-1990 & USA & 120 & $108(90)$ & $5(4.2)$ & $7(5.8)$ \\
\hline Eckstein et al. [15] & 2000 & Germany & 182 & $143(78.6)$ & $11(6)$ & $28(15.4)$ \\
\hline Jang et al. [26] & 2008-2010 & South Korea & 163 & $139(85.3)$ & - & $24(14.7)$ \\
\hline Kashkouli et al. [22] & $2003-2006$ & Iran & 303 & $280(92.4)$ & $23(7.5)$ & - \\
\hline Khoo et al. [27] & 1996-1999 & Singapore & 1020 & $1011(99.1)$ & $2(0.2)$ & $7(0.7)$ \\
\hline McKeag et al. [28] & $2006-2007$ & Wales & 47 & $44(93.6)$ & $3(6.4)$ & - \\
\hline Medghalchi et al. [29] & 2012-2014 & Iran & 103 & $83(80.5)$ & 19 (18.4) & $1(0.9)$ \\
\hline Mukasa et al. [30] & 2010-2010 & Japan & 238 & $210(88.2)$ & - & $28(11.8)$ \\
\hline Ponto et al. [31] & 1999-2012 & Germany & 610 & $584(95.7)$ & - & - \\
\hline Ponto et al. [32] & 2005-2012 & Germany & 461 & $441(95.6)$ & $12(2.6)$ & $8(1.7)$ \\
\hline Cozma et al. [33] & $1997-2005$ & Wales & 140 & $92(65.7)$ & $29(20.7)$ & 19 (13.6) \\
\hline
\end{tabular}

\section{Methodology assessment}

Many studies had been carried out studying TED. In our literature search, we found much information regarding this topic, including etiology, pathophysiology, diagnosis and evaluation, and treatment. A common premise, found in most of the studies, was the importance of an early diagnosis for a timely therapeutic approach and thus minimize the negative consequences for the patient. Besides, this disease appears to affect more women of reproductive age [8] and children and adolescents in a similar proportion or even slightly higher than adults [36].
Even though we found a lot of information to answer our question, we had to exclude most of the papers and studies we found, due to their lack of methodological quality. As explained in the methodology section, we used the Joanna Briggs guidelines to assess the methodological quality of each article we read. Only $63.33 \%$ of the studies were included after quality evaluation. Besides providing information about thyroid states in TED, we make a special call to the scientific community to take into account adequate scientific methodology using the standardized tools for each study design.

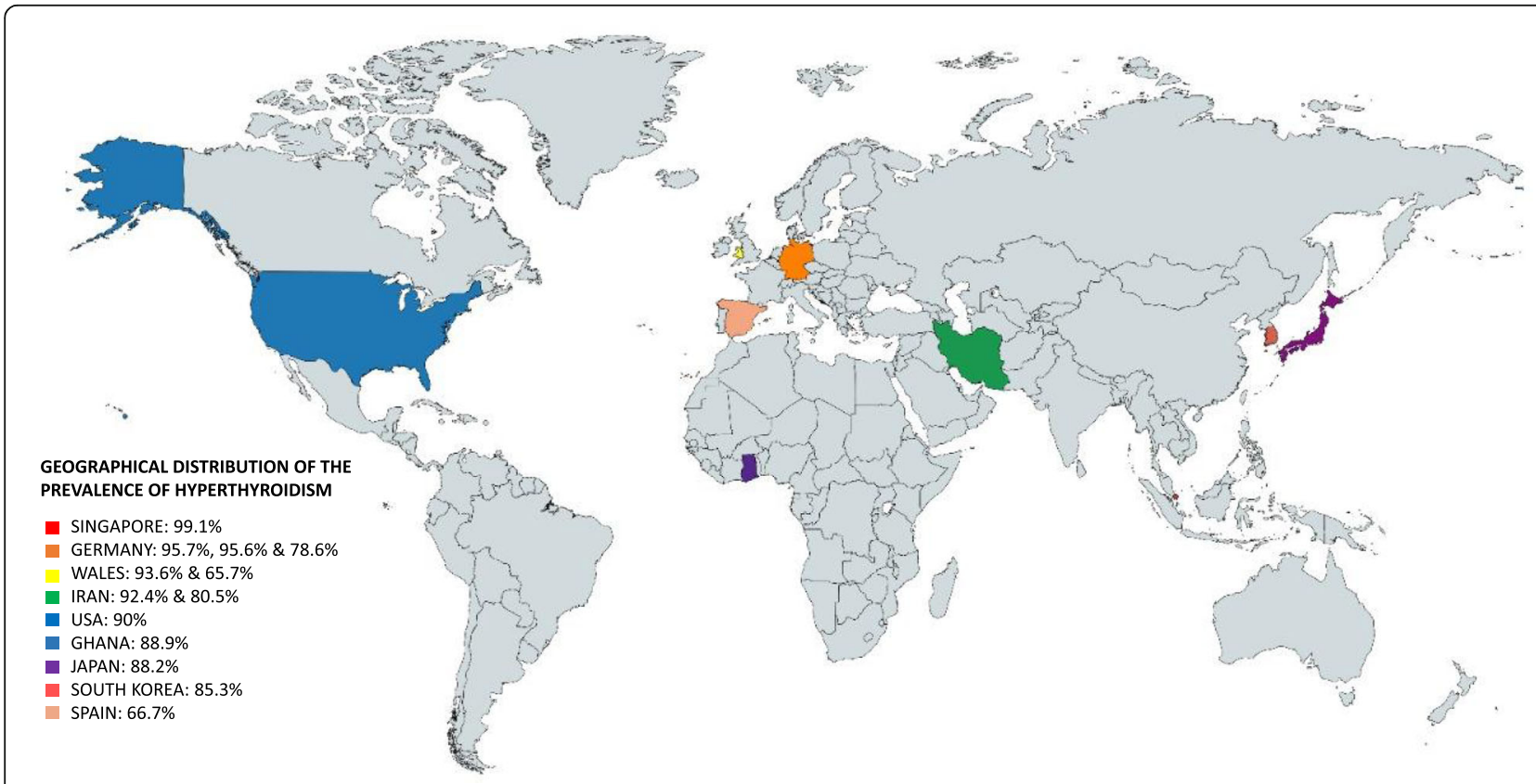

Fig. 2 Geographical distribution of prevalence of hyperthyroidism (Singapore, Germany, Wales, Iran, USA, Ghana, Japan, South Korea, and Spain) 


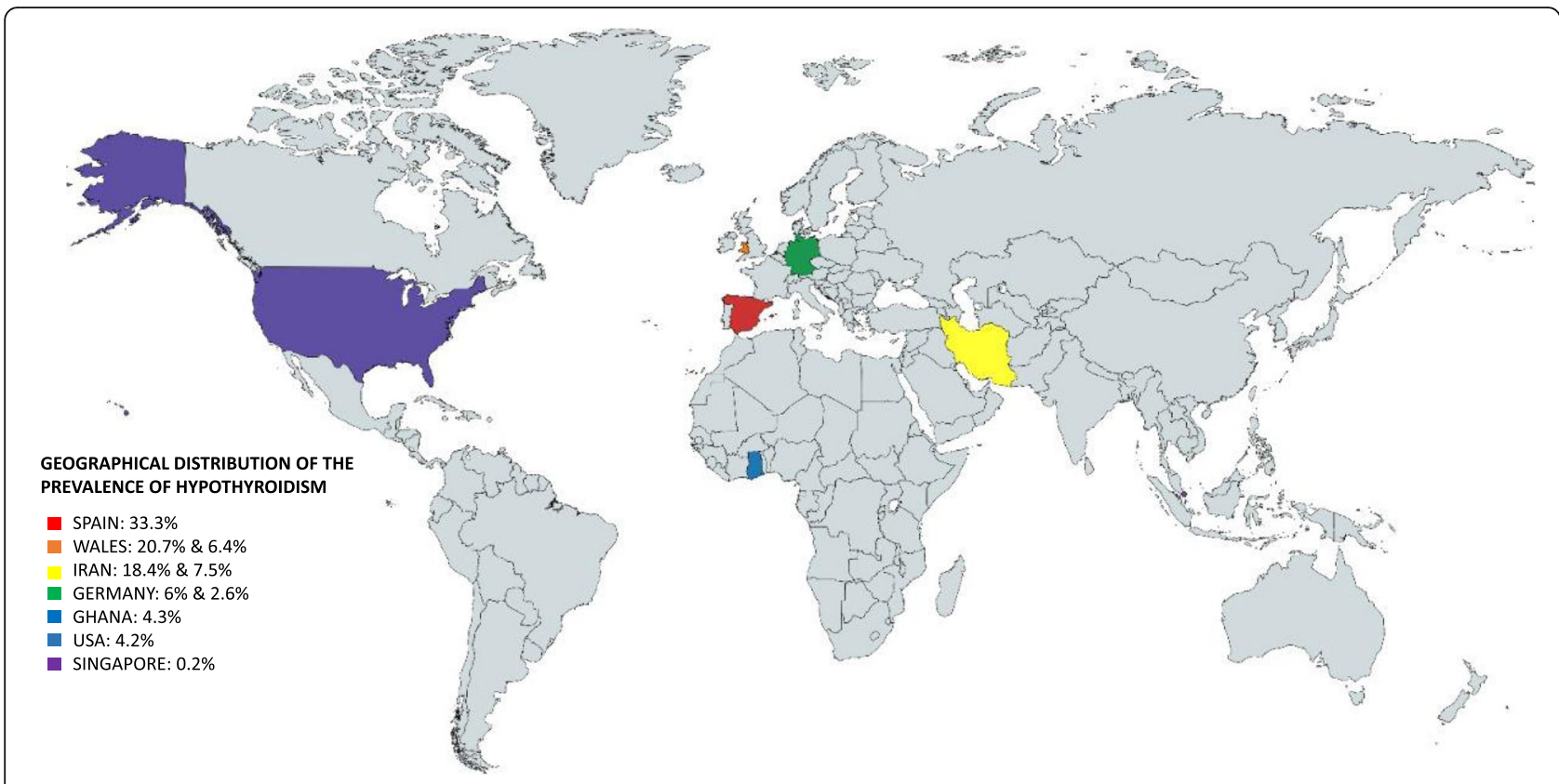

Fig. 3 Geographical distribution of prevalence of hypothyroidism (Spain, Wales, Iran, Germany, Ghana, USA, and Singapore)

In our literature search, we identified different studies that allowed the measurement of the prevalence of thyroid disorders in TED. We hypothesized that possible causes were the range of the sample size on each study, their geographical location, or their epigenetic factors influencing the results. Similarly, we found that 16 studies included
TED patients only associated with GD, underestimating the prevalence of hypothyroidism and euthyroidism.

\section{Clinical aspects}

Hyperthyroidism is a thyroid disorder that has been known as the most prevalent associated with TED. In

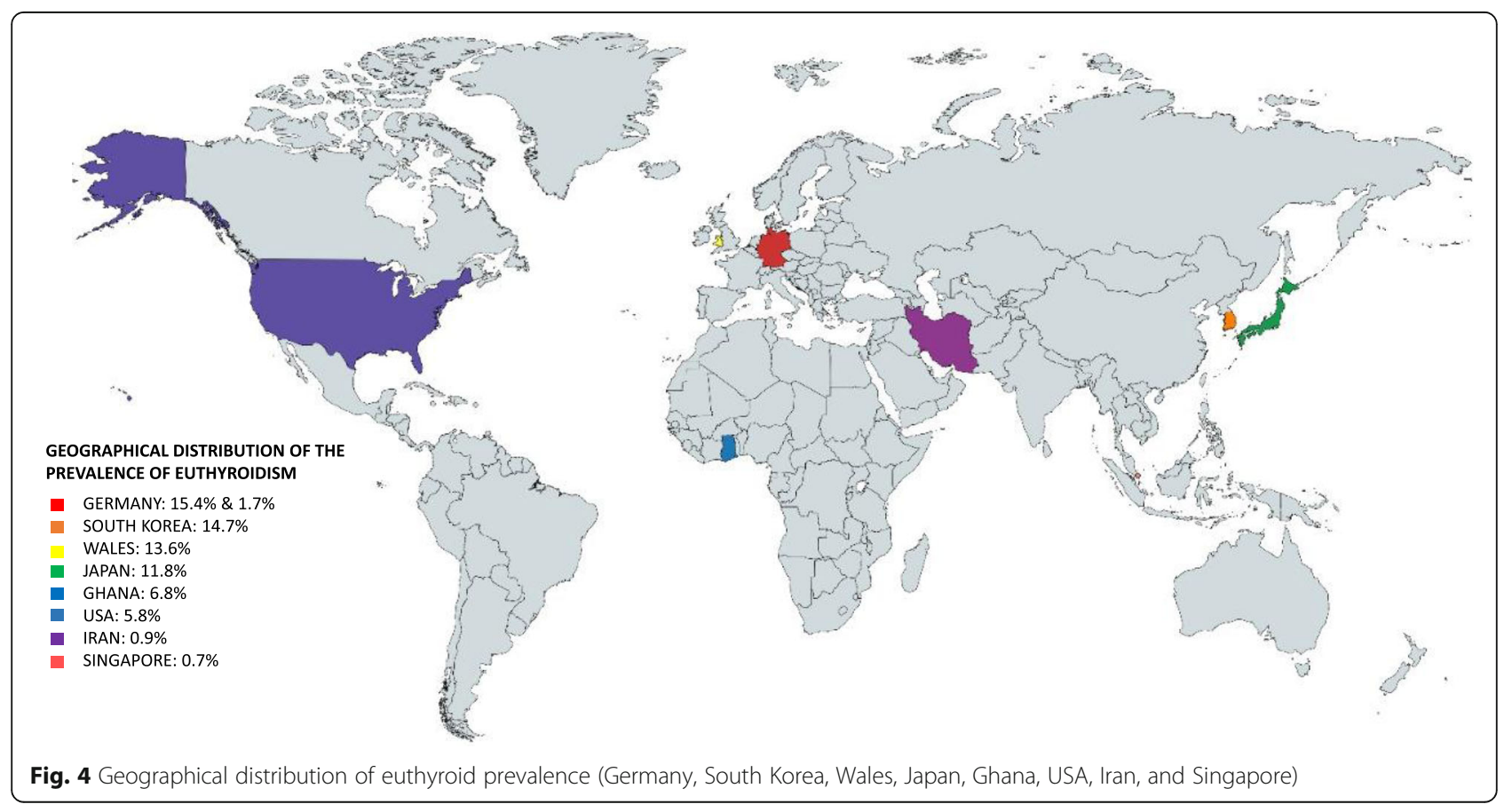


our study, the estimated prevalence was $86.2 \%$. The most frequent cause of hyperthyroidism is GD. Patients present with heat intolerance, sweating, weight loss, goiter, emotional lability, insomnia, hyperkinetic behavior, fatigue, weakness, tachycardia, and tremors [37].

Even though TED and GD share multiple similarities, they are two separate conditions. Although both involve the immune system, especially TRAbs, the target organ is different, in TED is the eye and orbit, while in GD is the thyroid gland.

In GD, autoreactive T cells against the TSHr escape both central and peripheral selection [38]. B cells develop into antibody-producing plasma cells in a process requiring second signals interacting with $\mathrm{T}$ cells, thus resulting in the production of cytokines such as interleukins $1 \beta, 6$, and 12; interferon- $\gamma$; tumor necrosis factor $\alpha$; CD40 ligand; and others. It promotes antibody secretion and $\mathrm{T}$ cell support of class switching [39]. After $\mathrm{T}$ cells have infiltrated the thyroid gland, thyroid epithelial cells express MHC class II molecules because of interferon- $\gamma$ action. Thus, they have the potential to present thyroid antigens to $\mathrm{T}$ cells, perpetuating the inflammatory process [10]. Activated autoantibodies of the IgG1 subclass, primarily generated by intrathyroidal B cells, are directed against the thyrotropin receptor. These antibodies stimulate thyroid hormone production that is uncontrolled by the hypothalamic-pituitary axis [40].

Genetic determinants conferring susceptibility to GD have been identified. These include genes encoding thyroglobulin, thyrotropin receptor, HLA-DR $\beta$-Arg74, the protein tyrosine phosphatase nonreceptor type 22 (PTPN22), and proteins involved in T cell signaling [4143]. Epigenetic factors such as dietary iodine, exposure to tobacco smoke, infections, emotional stress, and alemtuzumab therapy are also associated with GD [44].

In an investigation made by Yin et al., genetic association studies were performed in a highly characterized GO population and compared with patients with GD but no clinically apparent GO. They found that the allele and genotype frequencies were not statistically different between GO and non-GO patients, concluding that GO does not have a distinct genetic susceptibility to their eye disease [45]. Further studies should evaluate the influence of immunologic, genetic, and epigenetic factors in GO and TED in hypothyroid and euthyroid patients.

Hashimoto thyroiditis (HT) is part of a spectrum of thyroid autoimmune diseases, ranging from typically self-limiting focal forms [46] to other several clinicopathologic entities like hashitoxicosis. Most HT forms ultimately evolve into hypothyroidism (with systemic clinical manifestations of a slow metabolism), although, in the initial presentation, patients can be hyperthyroid or even euthyroid [47]. Moreover, HT is associated with disturbance in genes like the TSHr and with
IL1RNVNTR polymorphisms, and they also help as a prognostic indicator [48].

All forms of HT are characterized pathologically by lymphocyte $\mathrm{B}$ and $\mathrm{T}$ cell infiltration of the thyroid gland, as well as follicular helper $\mathrm{T}$ cells, increased in the thyroid peripheral blood. Furthermore, there is a clear correlation with antigen-specific $\mathrm{T}$ suppressor failure such as decreased sensitivity of CD4+ T cells to the inhibitory effect of TGF $\beta$ [46]. Antibodies found in HT not only make part of the pathogenesis of the disease but also help to establish a diagnosis and predict the development of hypothyroidism [46, 47].

Whereas thyroid-stimulating antibodies (TSAb) have a clear functional role activating TSHr in GD, it is also known the existence of blocking activity by the thyroidblocking antibodies (TBAb). The balance between TSAb/ $\mathrm{TBAb}$ determines disease presentation and fluctuating thyroid hormone levels between hyper or hypothyroidism in patients with thyroid autoimmune diseases [46].

Furthermore, few studies had demonstrated a strong association between functional TSAb and TED in patients with autoimmune HT. TSAb was highly prevalent in those with clinically overt and associated TED compared to HT patients without eye pathologies. Also, TSAb may be relevant to the pathophysiology of orbital involvement in HT [49].

The onset of the TED manifestation can be different between the hyperthyroid, hypothyroid, and euthyroid patients. Studies have demonstrated a lower involvement of the orbital-soft-tissue in patients with hypothyroid and euthyroid state [15]. Moreover, Jang et al. concluded that euthyroid patients have higher asymmetrical involvement (79.2\%) than hyperthyroid patients (27.3\%) [26].

\section{Limitations}

The diagnosis method of TED was variable between the studies, and the information they provided about the selection criteria was based on an assessment made by an ophthalmologist or disease specialized center, as shown in Table 1. Hence, we recognize that a limitation of our study is the lack of standardization in TED diagnosis among the included studies.

A small number of included works geographically dispersed and highly variable " $n$ " can be limitations of our work. Nevertheless, it was the result after the quality and data assessment of all the found articles.

\section{Conclusion}

We recommend to ophthalmologists to be aware of TED clinical signs and suspect it even if the patients have a normal thyroid function. The assessment for these patients should be based on orbital images, serum T3, free T4, TSH, TRAbs, and interdisciplinary management with the endocrinologist. 
There are many studies made in Asia, Germany, USA, and Wales, among other countries, but there is a lack of information about this disease in Latin American population. This is why we encourage researchers to obtain data from Latin American countries. Also, we strongly recommend performing primary studies following highquality methodology tools for future investigations.

\section{Supplementary information}

Supplementary information accompanies this paper at https://doi.org/10. 1186/s13643-020-01459-7.

Additional file 1. Search.

Additional file 2. JBI Critical Appraisal Checklist for Cohort Studies,

Additional file 3. JBI quality tools results for final selected articles.

\section{Abbreviations}

TD: Thyroid disease; USA: United States of America; TED: Thyroid eye disease; GD: Graves' disease; TSHr: Thyroid-stimulating hormone; IGF-1: Insulin-like growth factor 1; TSH: Thyroid-stimulating hormone; T4: Thyroxine; PRIS MA: Preferred Reporting Items for Systematic Reviews and meta-analysis; JMO: Juliana Muñoz Ortiz; MCSC: María Camila Sierra-Cote; ADLT: Alejandra de-la-Torre; EZB: Estefanía Zapata-Bravo; LW: Valenzuela-Vallejo; MGS: Marcela Gomez-Suarez; TRAbs: Thyrotropin receptor antibodies; HT: Hashimoto thyroiditis; TSAb: Thyroid-stimulating antibodies; TBAb: Thyroid-blocking antibodies

\section{Acknowledgements}

We thank Universidad del Rosario for financing the proofreading of this manuscript.

\section{Authors' contributions}

JMO: Management, research idea, protocol registration, protocol writing, title and abstract reading, manuscript writing and discussion, manuscript final approval. MCSC, EZB, LW: Protocol registration, protocol writing, title and abstract reading, quality evaluation, data extraction, manuscript writing and discussion, manuscript final approval. MAMN, PUR, JPDT, KAR: Title and abstract reading, quality evaluation, data extraction, manuscript writing and discussion, manuscript final approval. MGS: Methodology adviser. Protocol reviewing, results interpretation, manuscript final approval. ADLT:

Management, research idea, protocol writing, manuscript final approval, and thematic authority.

\section{Funding}

No funding was required to carry out this study.

\section{Availability of data and materials}

The datasets used and/or analyzed during the current study are available from the corresponding author on reasonable request.

\section{Ethics approval and consent to participate}

The present study was performed following the ethical principles for research involving human beings established by the Declaration of Helsinki, the Belmont Report, and Colombian Resolution 008430 of 1993. As it is a systematic review of the literature, it does not require approval by the ethics committee.

\section{Consent for publication}

Not applicable.

\section{Competing interests}

The authors declare that they have no competing interests.

\section{Author details}

'Escuela Barraquer Research Group, Escuela Superior de Oftalmología del Instituto Barraquer de América, Avenida Calle 100 No. 18A - 51, Bogotá, Colombia. ${ }^{2}$ Research Group in Neurosciences NeURos, Escuela de Medicina y
Ciencias de la Salud, Universidad del Rosario, Carrera 24 \# 63C 69, Bogotá, Colombia.

Received: 8 June 2020 Accepted: 14 August 2020

Published online: 01 September 2020

\section{References}

1. General Information/Press Room [Internet]. American Thyroid Association. [cited 2020 Apr 7]. Available from: https://www.thyroid.org/media-main/ press-room/.

2. Kvetny J. The significance of clinical euthyroidism on reference range for thyroid hormones. Eur J Intern Med. 2003;14:315-20.

3. De Leo S, Lee S, Braverman L. Hyperthyroidism. Lancet. 2016:388:906-18.

4. Chaker L, Bianco AC, Jonklaas J, Peeters RP. Hypothyroidism. Lancet. 2017; 390:1550-62.

5. Gamblin GT, Harper DG, Galentine P, Buck DR, Chernow B, Eil C. Prevalence of increased intraocular pressure in Graves' disease-evidence of frequent subclinical ophthalmopathy. N Engl J Med. 1983;308:420-4.

6. Bahn RS. Graves' ophthalmopathy. N Engl J Med. 2010;362:726-38.

7. Prummel MF, Wiersinga WM, Mounts MP, Koornneef $L$, Berghout A, van der Gaag R. Effect of abnormal thyroid function on the severity of Graves' ophthalmopathy. Arch Intern Med. 1990;150:1098-101.

8. Turck N, Eperon S, De Los Angeles Gracia M, Obéric A, Hamédani M. Thyroid-associated orbitopathy and biomarkers: where we are and what we can hope for the future. Dis Markers. Hindawi. 2018;2018:7010196.

9. Cao HJ, Wang HS, Zhang Y, Lin HY, Phipps RP, Smith TJ. Activation of human orbital fibroblasts through CD40 engagement results in a dramatic induction of hyaluronan synthesis and prostaglandin endoperoxide $\mathrm{H}$ synthase-2 expression. Insights into potential pathogenic mechanisms of thyroid-associated ophthalmopathy. J Biol Chem. 1998;273:29615-25.

10. Smith TJ, Hegedus L. Graves' disease. N Engl J Med. 2016;375:1552-65.

11. Pritchard J, Han R, Horst N, Cruikshank WW, Smith TJ. Immunoglobulin activation of $\mathrm{T}$ cell chemoattractant expression in fibroblasts from patients with Graves' disease is mediated through the insulin-like growth factor I receptor pathway. J Immunol. 2003;170:6348-54.

12. Douglas RS, Gianoukakis AG, Kamat S, Smith TJ. Aberrant expression of the insulin-like growth factor-1 receptor by T cells from patients with Graves' disease may carry functional consequences for disease pathogenesis. J Immunol. 2007:178:3281-7.

13. Douglas RS, Naik V, Hwang CJ, Afifiyan NF, Gianoukakis AG, Sand D, et al. B cells from patients with Graves' disease aberrantly express the IGF-1 receptor: implications for disease pathogenesis. J Immunol. 2008;181:5768-74.

14. Bartley GB, Fatourechi V, Kadrmas EF, Jacobsen SJ, Ilstrup DM, Garrity JA, et al. Clinical features of Graves' ophthalmopathy in an incidence cohort. Am J Ophthalmol. 1996;121:284-90.

15. Eckstein AK, Lösch C, Glowacka D, Schott M, Mann K, Esser J, et al. Euthyroid and primarily hypothyroid patients develop milder and significantly more asymmetrical Graves ophthalmopathy. Br J Ophthalmol. 2009;93:1052-6.

16. Kotwal A, Stan M. Current and future treatments for Graves' disease and Graves' ophthalmopathy. Horm Metab Res. 2018:50:871-86.

17. Douglas RS, Kahaly GJ, Patel A, Sile S, Thompson EH, Perdok R, et al Teprotumumab for the treatment of active thyroid eye disease. N Engl J Med. 2020;382:341-52

18. Garber JR, Cobin RH, Gharib H, Hennessey JV Klein I, Mechanick II, et al. Clinical practice guidelines for hypothyroidism in adults: cosponsored by the American Association of Clinical Endocrinologists and the American Thyroid Association. Thyroid. 2012;22:1200-35.

19. Moher D, Shamseer L, Clarke M, Ghersi D, Liberati A, Petticrew M, et al. Preferred reporting items for systematic review and meta-analysis protocols (PRISMA-P). Syst Rev [Internet]. 2015 [cited 2020 Apr 7]:4. Available from: https://www.ncbi.nlm.nih.gov/pubmed/25554246.

20. ebp - Critical Appraisal Tools | Joanna Briggs Institute [Internet]. [cited 2020 Apr 7]. Available from: https://joannabriggs.org/ebp/critical_appraisal_tools.

21. Munn Z, Moola S, Lisy K, Riitano D, Tufanaru C. Methodological guidance for systematic reviews of observational epidemiological studies reporting prevalence and cumulative incidence data. Int J Evid Based Healthc. 2015; 13:147-53.

22. Kashkouli MB, Pakdel F, Kiavash V, Heidari I, Heirati A, Jam S. Hyperthyroid vs hypothyroid eye disease: the same severity and activity. Eye (Lond). 2011;25: 1442-6. 
23. Kashkouli MB, Kaghazkanani R, Heidari I, Ketabi N, Jam S, Azarnia S, et al. Bilateral versus unilateral thyroid eye disease. Indian J Ophthalmol. Wolters Kluwer--Medknow Publications. 2011;59:363.

24. Ackuaku-Dogbe E, Akpalu J, Abaidoo B. Epidemiology and clinical features of thyroid-associated orbitopathy in Accra. Middle East Afr J Ophthalmol. 2017:24:183-9.

25. Expósito MRA, Moreno MÁG, Moreno PM, Sánchez IP, Jiménez CM, López PB. Evaluación de la efectividad del tratamiento con glucocorticoides intravenosos en la oftalmopatía de Graves. Endocrinología y Nutrición Elsevier. 2013;60:10-4.

26. Jang SY, Lee SY, Lee EJ, Yoon JS. Clinical features of thyroid-associated ophthalmopathy in clinically euthyroid Korean patients. Eye (Lond). 2012;26: 1263-9.

27. Khoo DH, Eng PH, Ho SC, Tai ES, Morgenthaler NG, Seah LL, et al. Graves' ophthalmopathy in the absence of elevated free thyroxine and triiodothyronine levels: prevalence, natural history, and thyrotropin receptor antibody levels. Thyroid. 2000;10:1093-100.

28. McKeag D, Lane C, Lazarus JH, Baldeschi L, Boboridis K, Dickinson AJ, et al. Clinical features of dysthyroid optic neuropathy: a European Group on Graves' Orbitopathy (EUGOGO) survey. Br J Ophthalmol. 2007;91:455-8.

29. Medghalchi A, Akbari M, Alizadeh Y, Moghadam RS. The epidemiological characteristics of patients with thyroid eye disease in a referral center in northern Iran. J Curr Ophthalmol. 2018;30:353-8.

30. Mukasa K, Yoshimura Noh J, Kouzaki A, Ohye H, Kunii Y, Watanabe N, et al. TSH receptor antibody titers measured with a third-generation assay did not reflect the activity of Graves' ophthalmopathy in untreated Japanese Graves' disease patients. Endocr J. 2016;63:151-7.

31. Ponto KA, Schuppan D, Zwiener I, Binder H, Mirshahi A, Diana T, et al. Thyroid-associated orbitopathy is linked to gastrointestinal autoimmunity. Clin Exp Immunol. 2014;178:57-64.

32. Ponto KA, Binder H, Diana T, Matheis N, Otto AF, Pitz S, et al. Prevalence, phenotype, and psychosocial well-being in euthyroid/hypothyroid thyroidassociated orbitopathy. Thyroid. 2015;25:942-8.

33. Cozma I, Cozma L, Boyce R, Ludgate ME, Lazarus JH, Lane C. Variation in thyroid status in patients with Graves 'orbitopathy. Acta Endocrinologica (1841-0987). 2009;5:191-8.

34. Estcourt S, Quinn AG, Vaidya B. Quality of life in thyroid eye disease: Impact of quality of care. Eur J Endocrinol Suppl. 2011;164:649-55.

35. McAlinden C. An overview of thyroid eye disease. Eye Vis (Lond). 2014;1:9.

36. Szczapa-Jagustyn J, Gotz-Wieckowska A, Kociecki J. An update on thyroidassociated ophthalmopathy in children and adolescents. J Pediatr Endocrinol Metab. 2016;29:1115-22.

37. Campi I, Salvi M. Graves' disease; 2018

38. Martin A, Schwartz AE, Friedman EW, Davies TF. Successful production of intrathyroidal human T cell hybridomas: evidence for intact helper T cell function in Graves' disease. J Clin Endocrinol Metab. 1989;69:1104-8.

39. Nagata K, Nakayama Y, Higaki K, Ochi M, Kanai K, Matsushita M, et al. Reactivation of persistent Epstein-Barr virus (EBV) causes secretion of thyrotropin receptor antibodies (TRAbs) in EBV-infected B lymphocytes with TRAbs on their surface. Autoimmunity. 2015;48:328-35.

40. Weetman AP, Yateman ME, Ealey PA, Black CM, Reimer CB, Williams RCJ, et al. Thyroid-stimulating antibody activity between different immunoglobulin G subclasses. J Clin Invest. 1990:86:723-7.

41. Tomer Y. Mechanisms of autoimmune thyroid diseases: from genetics to epigenetics. Annu Rev Pathol. 2014;9:147-56.

42. Brix TH, Kyvik KO, Christensen K, Hegedüs L. Evidence for a major role of heredity in Graves' disease: a population-based study of two Danish twin cohorts. J Clin Endocrinol Metabol. 2001;86:930-4.

43. Limbach M, Saare M, Tserel L, Kisand K, Eglit T, Sauer S, et al. Epigenetic profiling in CD4+ and CD8+ T cells from Graves' disease patients reveals changes in genes associated with $T$ cell receptor signaling. J Autoimmun. 2016:67:46-56

44. Coles AJ, Wing M, Smith S, Coraddu F, Greer S, Taylor C, et al. Pulsed monoclonal antibody treatment and autoimmune thyroid disease in multiple sclerosis. Lancet Elsevier. 1999;354:1691-5.

45. Yin X, Latif R, Bahn R, Davies TF. Genetic profiling in Graves' disease: further evidence for lack of a distinct genetic contribution to Graves' ophthalmopathy. Thyroid. 2012;22:730-6.

46. Ajjan RA, Weetman AP. The pathogenesis of Hashimoto's thyroiditis: further developments in our understanding. Horm Metab Res. (c) Georg Thieme Verlag KG. 2015;47:702-10.
47. Caturegli P, De Remigis A, Rose N. Hashimoto thyroiditis: clinical and diagnostic criteria. Autoimmun Rev Elsevier. 2014;13:391-7.

48. Zaaber I, Mestiri S, Marmouch H, Mahjoub S, Abid N, Hassine M, et al. Polymorphisms in TSHR and IL1RN genes and the risk and prognosis of Hashimoto's thyroiditis. Autoimmunity Taylor \& Francis. 2014;47:113-8.

49. Kahaly GJ, Diana T, Glang J, Kanitz M, Pitz S, Konig J. Thyroid stimulating antibodies are highly prevalent in Hashimoto's thyroiditis and associated orbitopathy. J Clin Endocrinol Metab. 2016;101:1998-2004.

\section{Publisher's Note}

Springer Nature remains neutral with regard to jurisdictional claims in published maps and institutional affiliations.

\section{Ready to submit your research? Choose BMC and benefit from:}

- fast, convenient online submission

- thorough peer review by experienced researchers in your field

- rapid publication on acceptance

- support for research data, including large and complex data types

- gold Open Access which fosters wider collaboration and increased citations

- maximum visibility for your research: over $100 \mathrm{M}$ website views per year

At BMC, research is always in progress.

Learn more biomedcentral.com/submissions 